\title{
Editorial
}

\section{J. Carrano}

Accepted: 25 January 2021 / Published online: 9 February 2021

(C) The Author(s), under exclusive licence to Springer Nature B.V. part of Springer Nature 2021

Dear Authors, Reviewers, Associate Editors, Board Members, Editorial Staff and Readers of BioMetals, As the new Editor-in-Chief I want first to thank everyone for their service to the journal and to wish everyone a Happy New Year. Let us hope that it will be better than the last. After all as the sailors say, "we are bound for better weather" and hopefully with many viable vaccines we will get past this COVID pandemic and return to something like normal. I also want to take this time to thank our previous Editor-inChief and my personal very good friend, Prof. Dr. Günther Winkelmann for his long service to the journal and to wish both he and his wife Isa a well deserved retirement. In fact, for those that do not know, Günther was until late last year the ONLY Editor-in-Chief the journal has known. Indeed, the journal was founded by Günther in 1988 under the name Biology of Metals which in 1992 changed to the name BioMetals that we know today. In 1988 bioinorganic chemistry was a relatively new field and Günther, who was part of the "siderophore core" at the University of Tübingen in Germany along with Volkmar Braun, Klaus Hantke and others, saw the need for another journal specializing in this new field (at the time as I recollect there was just one such

C. J. Carrano $(\bowtie)$

San Diego State University, San Diego,

CA, USA

e-mail: ccarrano@sdsu.edu

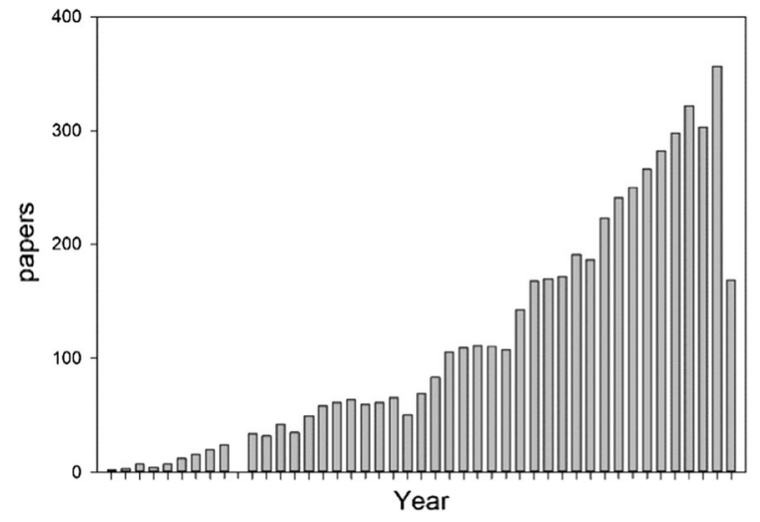

Fig. 1 Number of papers with the word sideophore in the title or abstract from 1976 to 2020

journal). Since those early beginnings the field has exploded and using siderophores as just one example has seen exponential growth (Fig. 1). As we move into the journals 33rd year my hope is that it will continue to thrive and indeed move forward. A special reminder to International BioMetals Society (IBS) members that this is YOUR journal and I hope that many of you will consider publishing some of your best work here and continue to help improve the journals metrics. We can only do it together. Again best wishes for a Happy and prosperous New Year.

Publisher's Note Springer Nature remains neutral with regard to jurisdictional claims in published maps and institutional affiliations. 